\title{
Sobre rostos e distâncias: deslocamentos nas narrativas bíblicas de Sara e Rebeca
}

\begin{abstract}
Altamir Celio de Andrade ${ }^{1}$
Resumo: Este artigo examina as narrativas bíblicas sobre Sara e Rebeca. Essas personagens, presentes no Livro do Gênesis, são simbólicas para se pensar o deslocamento espacial como indicativo de mudanças internas, isto é, questões psicológicas que acompanharão essas mulheres ao longo de suas experiências em terras estrangeiras. O Gênesis inicia as páginas de uma obra clássica: a Bíblia. Tal obra é emblemática e influenciadora do pensamento ocidental, como alertaram Erich Auerbach, Northrop Frye, Robert Alter e Harold Bloom, dentre outros. As histórias dessas duas mulheres são referenciais para a leitura de um texto fundador dos antigos hebreus, uma vez que, nelas, Israel reconhecerá suas origens e o sentido de sua existência como povo. A investigação proposta se deixará guiar pelos conceitos de exílio e deslocamento, utilizados contemporaneamente no contexto dos estudos literários, culturais e filosóficos, sobretudo a partir de Stuart Hall e Jean-Luc Nancy. Portanto, o estudo do comportamento dessas duas personagens, bem como de suas estratégias de sobrevivência, permite compreender o deslocamento dos seres humanos em todos os tempos e em diversas partes do mundo. O sofrimento, a astúcia e as identidades de Sara e Rebeca permitem reler a história do antigo Israel de forma vívida, estética e empolgante.
\end{abstract}

Palavras-chave: Sara. Rebeca. Deslocamento. Identidade. Bíblia.

\section{Introdução}

Propor uma relação entre o texto bíblico e os estudos literários e culturais é uma tarefa relevante para os momentos atuais. Tal empreendimento assemelha-se à busca de letras capitulares em um pergaminho sobre o qual muito já foi escrito, um palimpsesto. A força dos textos da Bíblia pode ser sentida quando se nota como esses mesmos textos atravessaram os séculos com o vigor e a profundidade de suas narrativas. Suas interpretações influenciaram e moldaram o imaginário das culturas de origem judaico-cristã e isso vem sendo demonstrado através de pesquisas de estudiosos contemporâneos. Seus exames contribuíram e contribuem para o surgimento de pensamentos e teorias que ultrapassaram as fronteiras do campo do sagrado e do religioso.

\footnotetext{
${ }^{1}$ Doutor em Letras: Estudos Literários (Universidade Federal de Juiz de Fora - UFJF). Mestre em Teologia Bíblica (Pontifícia Universidade Católica do Rio de Janeiro - PUC-Rio). Docente do Centro de Ensino Superior de Juiz de Fora - CES/JF, MG, Brasil. E-mail: altalogos@gmail.com. (1) https://orcid.org/0000-0002-4802-2714
} 
Partindo de narrativas encontradas no Antigo Testamento, mais precisamente no Gênesis, este artigo concentra-se em narrativas ao redor de duas mulheres: $\operatorname{Sara}^{2}$ e Rebeca. Essas mulheres - a exemplo de grande parte das personagens femininas que habitam os dois primeiros livros da Bíblia - têm em comum não só o gênero, como também o fato de estarem deslocadas de sua terra natal. Além disso, elas estão sujeitas à figura masculina de Abraão: a primeira é sua esposa e a segunda, sua nora.

As discussões estabelecidas a partir dessas narrativas, embora se avizinhem dos estudos que abordam a questão do gênero, não se reduzem a isso, uma vez que essas narrativas solicitam, elas próprias, uma aproximação de questões candentes abordadas no âmbito dos estudos culturais, da crítica literária e da filosofia, suscitando a mobilização de conceitos caros às críticas literária e cultural e ao pensamento filosófico na contemporaneidade, quais sejam, os de exílio e deslocamento. Assim, ressalta-se que as teorias que perpassam o artigo são determinadas pelos textos que estão sob estudo e não um simples enquadramento desses textos ao que se quer investigar.

Isto posto, torna-se relevante esclarecer que esta investigação, quando cita as narrativas bíblicas especificamente estudadas, procura apresentar uma tradução diretamente do hebraico. Com isso, busca-se oferecer a possibilidade de uma compreensão mais ampla dos rastros deixados pela escrita hebraica na configuração das traduções modernas. Para tanto, será usado como texto crítico de base, a Bíblia Hebraica Stuttgartensia, editada por Karl Elliger e Wilhelm Rudolph em 1967/77.

\section{A Bíblia como literatura}

A abordagem da Bíblia pelo viés da literatura não é uma novidade no âmbito das pesquisas teológicas e de crítica literária. As primeiras interessam-se pela busca da mensagem ou mensagens dos textos analisados, dedicando-se a exames sincrônicos e diacrônicas dos mesmos. A análise diacrônica da Bíblia é o principal caminho trilhado pelos estudiosos desde

\footnotetext{
${ }^{2}$ A Bíblia apresenta duas formas para os nomes de Abraão e de Sara. Inicialmente, ele é apresentado como Abrão e ela como Sarai, mas em Gênesis 17,5 e 17,15 seus nomes são mudados, respectivamente. Fica claro, no entanto, que essa mudança se deve a razões teológicas. Assim sendo, optamos, neste artigo, por grafá-los simplesmente como Abraão e Sara.
} 
o século XVIII. Embora amplamente usada, não deixa de ser, também, muitas vezes criticada e até abandonada em busca de uma análise que considere o texto em sincronia, isto é, a narrativa em sua forma final.

A Bíblia, como uma arte compósita, apresenta diversos segmentos narrativos independentes, inclusive dentro de um mesmo livro. Notamos, assim, um grande desafio quando buscamos delimitar um texto e compreender as fronteiras que se estendem ou se estreitam à medida que lemos tais textos. Existem glosas, costuras e fusões que podem estar na origem de equívocos interpretativos. No que se refere às abordagens sincrônicas, a atenção se volta para a análise narrativa, que busca ler o texto em um arco mais amplo, cuja principal característica (contrastando com a exegese clássica de crítica histórica) está alicerçada em uma visão de conjunto do texto, analisando-o sem fragmentá-lo ou datá-lo em partes, como se fosse meramente um objeto de arqueologia. Busca, dessa forma, desvelar as lacunas do texto, avaliando as tensões geradas pela narrativa e procurando entender o alcance das mesmas.

Consequentemente, ao invés de se perder em um trabalho exaustivo de verificação de cada unidade textual (como fazem os métodos histórico-críticos), procura divisar o alcance desses elementos na direção do leitor. A análise narrativa constitui-se, assim, na principal forma de abordagem que privilegia o aspecto literário da Bíblia. É nesse contexto que se encontram importantes autores da abordagem narrativa da Bíblia, como Erich Auerbach, Northrop Frye, Robert Alter e Harold Bloom, de cujas pesquisas somos devedores.

O primeiro é um nome referencial na leitura da Bíblia sob o olhar da crítica literária. Em Mimesis: A Representação da realidade na literatura ocidental, editado no Brasil pela primeira vez em 1971, Auerbach dedicou parte do ensaio “A cicatriz de Ulisses" para fazer uma comparação entre Gn22 (o texto sobre o sacrifício de Isaac) e o livro XIX da Odisseia. Ali, o autor diferenciou e particularizou as características dos personagens, tanto em Homero, como da Bíblia em geral. Depois dele, Northrop Frye publicou, em 1981, O Código dos Códigos: a Bíblia e a Literatura, lançado no Brasil em 2004). O percurso feito por Frye, ao estudar as estruturas imaginativas da Bíblia contribuiu para o entendimento, não só de uma estética do texto, mas de um universo de personagens que, com suas vozes e silêncios, são matriciais para uma percepção mais abrangente dos temas do exílio, do deslocamento e da hospitalidade. 


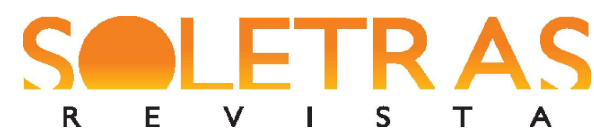

N. 38 - 2019.2 - ALTAMIR CELIO DE ANDRADE

Bem próximo a Frye, Robert Alter publicou (também em 1981), A Arte da narrativa bíblica (no Brasil em 2007). Nesta obra, ele investigou, entre outros assuntos, as relações entre a história sagrada na Bíblia e seus relatos, sobretudo no que tange aos seus aspectos ficcionais. Muito embora essa perspectiva possa gerar certa resistência naqueles que abordam a Bíblia sem perceber seu caráter de literatura, é legítimo afirmar, com Alter, que os escritos, particularmente do Antigo Testamento, "buscavam revelar, mediante o processo narrativo, a realização dos propósitos divinos nos acontecimentos históricos” (ALTER, 2007, p. 59).

Finalmente, Harold Bloom trouxe a público, em 1990, uma obra chamada O Livro de $J$ (no Brasil, 1992). A tese apresentada pelo autor ao longo das linhas desse livro é a de que os estratos mais antigos da Bíblia Hebraica poderiam ter uma autoria feminina em sua gênese. Essa mulher, segundo Bloom, receberia o nome de Javista, donde J. Bloom explana sobre as redações, atualizações e correções que foram feitas nos textos ao longo dos tempos e, sobretudo, após o exílio de Judá (reino do Sul de Israel, com capital em Jerusalém) para a Babilônia entre após 597 a.C.

De tudo isso se depreende que a Bíblia já é, por longa data, uma obra matricial nos estudos de literatura. Assim sendo, não se trata mais de discutir se é ou não literatura porque a sua abordagem “de um ponto de vista literário não é de per si ilegítimo: nenhum livro poderia ter uma influência literária tão pertinaz sem possuir ele próprio, características de obra literária" (FRYE, 2004, p. 14). Esse inventário permite afirmar o quanto esses autores abriram caminho para um olhar literário sobre a Bíblia e que se distanciasse de um objetivo teológico ou meramente arqueológico. O Século XVIII testemunhou o desenvolvimento das pesquisas em arqueologia de textos antigos que acabaram por se estender ao próprio texto bíblico. Com isso, nasceu um conjunto de métodos que influenciou sobremaneira esse campo da análise da Bíblia: os métodos histórico-críticos.

É fato que a crítica literária bíblica, no interior desses métodos, apontava para esta possibilidade. No entanto, essa forma de crítica ainda não pode ser avaliada em pé de igualdade com as modernas análises, embora as tenha influenciado. Nesse sentido, ela depende de regulamentações e critérios específicos para abordar os textos bíblicos. Com isso se observa que, desde o século XVIII, já se buscava compreender o texto bíblico com indagações que incluíam a pergunta sobre o autor, as fontes deste autor, o momento e local onde o texto foi escrito. Com o desenvolvimento dessas percepções, ao longo dos séculos, a 
atenção de pesquisadores e leitores que não trabalhavam diretamente com a Bíblia foi despertada para o seu conteúdo.

É aqui que se torna imperativo exaltar o trabalho dos críticos indicados neste exame, qual seja, uma análise comparativa com outros corpora da literatura mundial que se estabeleceu como norteadora e fundante. Fica evidente, portanto, que o texto da Bíblia se insere em uma via de mão dupla: aquela em que sua interpretação visa a uma abordagem de cunho moral, doutrinário e espiritual, e outra que dá ênfase aos aspectos literários, na qual se destacam suas características estéticas. Iniciou-se, assim, um olhar sobre a Bíblia a partir de estudos sobre literatura comparada que se interessavam, também, pelas características formais de sua construção.

O que se segue, portanto, é uma leitura das narrativas sobre Sara e Rebeca, buscando ler o texto bíblico como um relato literariamente elaborado da história dos primeiros povos da Bíblia. Assim, procura-se analisá-los a partir de conceitos que são utilizados para abordarem as produções literárias e culturais de indivíduos e grupos de pessoas que, por motivos diversos, experimentaram situações como as de deslocamentos e errâncias, inerentes a esses povos.

\section{O caminho sobre Sara: deslocamento e exílio}

Desde o início da narrativa ( $G n$ 11,26), um fio vermelho vem acompanhando o desenrolar dos fatos. Esse fio é a indicação da terra. A terra da parentela aparece em $G n$ 11,28, quando se diz que nela morreu Haran (pai de Abraão). No início do capítulo 12, o tema é retomado com toda a força quando a promessa divina é de terra. Sai-se de uma terra com destino a outra terra que é mostrada e, portanto, prometida ${ }^{3}$.

As duas grandes diásporas que se seguirão, na história desse povo, estão necessariamente sob o emblema da perda da terra e da sua retomada: êxodo do Egito (séc. XIII a.C.) e exílio para a Babilônia (séc. VI a.C.). A família de Abraão encontra-se, assim, entre duas terras: uma deixada e outra prometida. Sara vai com Abraão nessa barcaça à deriva. Se para ele tudo é novidade e apreensão, para ela não é menos difícil, uma vez que carrega,

\footnotetext{
${ }^{3}$ Aqui pode ser estabelecido um paralelo importante com a (quase) chegada de Moisés na terra prometida, em Deuteronômio 34. Ali, a terra lhe é mostrada, mas ele não tomará posse da mesma.
} 


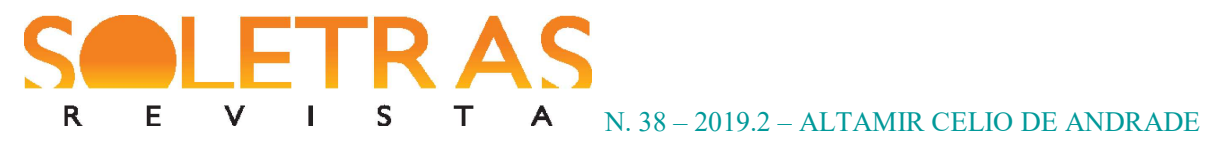

também, o desconforto de não ter um filho. Aqui, parece ser bem apropriada a reflexão de José Saramago, em A Jangada de Pedra (1980), quando comenta o êxodo de seus cinco personagens (Maria Guavaíra, Joana Carda, Pedro Orce, Joaquim Sassa e José Anaiço):

A estrada, em poucos dias, tornou-se num mundo fora do mundo, como qualquer homem que, no mundo estando, se descobre ele próprio um mundo, e nem é difícil, basta fazer um pouco de solidão à sua volta, como estes viajantes que, indo juntos, vão sós (SARAMAGO, 1980, p. 262).

Quando se cruza fronteiras para ir além ou portas para saídas ao desconhecido, parece que se está diante de uma simbologia intrínseca do que seriam as mudanças no interior das pessoas que se lançam nessas jornadas. As mudanças mais significativas, portanto, parecem estar ocorrendo de forma subjetiva, sugerindo novas maneiras de pensar e de habitar o mundo. São portas que se abrem para sair e chegar; em uma prodigalidade de sentidos que, vistos de modo conjunto, permitem perceber a identidade de um povo inteiro ou de cada pessoa em particular.

É por isso, talvez, que a questão do estrangeiro não passa ao largo de uma discussão sobre o deslocamento humano em todos os tempos e lugares. O deslocamento geográfico converte-se no indicador das transformações humanas que são complexas, exigindo inusitadas decisões e saídas criativas. Daí resulta conflito: se alguém sai, alguém fica. Quando se sai, porém, necessita-se de acolhida em um outro lugar; quando se movimenta, o conflito se instaura.

Stuart Hall, em Da Diáspora: identidades e mediações culturais (2003), quando discorre sobre a diáspora caribenha, acena para o aspecto matricial dos constantes exílios judaicos, ao afirmar que, no Antigo Testamento, já

encontramos o análogo, crucial para a nossa história, do "povo escolhido", violentamente levado à escravidão no "Egito"; de seu "sofrimento' nas mãos da "Babilônia"; da liderança de Moisés, seguida pelo Grande Êxodo (HALL, 2003, p. 28-29).

O que se pode saber a respeito de Sara? Ora, logo no começo do breve relato de $G n$ 11, 27-32, somos informados deque foi tomada por Abraão, que é estéril e que não tinha filhos. Aparentemente, o fato de a narrativa observar que não tinha filho pode dar a impressão de uma redundância com a indicação precisa de esterilidade. No entanto, não é o que se 


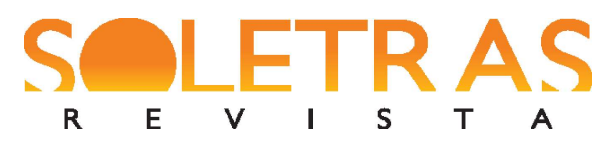

N. 38 - 2019.2 - ALTAMIR CELIO DE ANDRADE

verifica. Suzana Chwarts ressalta que o termo hebraico 'aqarah (comumente traduzido por “estéril”), não está vinculado única e exclusivamente ao sentido de não poder gerar filhos. Ela lembra que três grandes matriarcas carregam consigo essa intrigante palavra na apresentação de suas vidas: Sara, Rebeca e Raquel. Chwarts recorda, também, que as várias explicações dos que comentaram esses textos recaíram sobre a importância dos heróis que foram gerados dessas mulheres, negligenciando a sua identidade e o seu valor. Para ela, ao contrário da simples sugestão de 'aqarah significar estéril, o termo estaria ligado a uma etimologia bem mais antiga, que o colocaria em relação com a terra, isto é, uma etimologia ('qr) que, no ambiente da agricultura, aludiria a um desenraizamento, a um arrancar pela raiz (CHWARTS, 2004, p. 24).

Um pormenor das observações de Chwarts tem seu contorno ampliado quando a pesquisadora afirma que, assim como as mulheres indicadas "são inicialmente inférteis, sem filhos", da mesma forma os patriarcas se tornam "desenraizados, desarraigados, residentes temporários; e a terra, árida, é profundamente marcada pela fome” (CHWARTS, 2004, p. 28). A autora observa, também, que não é feita qualquer referência à Sara no versículo em que ela é apresentada (Gn 11,29). Isso evidencia uma completa falta de identidade: uma mulher sem passado e sem possibilidade de gerar o futuro.

É assim que Sara permanecerá nas narrativas que se seguem, isto é, uma mulher sem identidade e, portanto, sem raiz. As narrativas, no entanto, insistem em demonstrar como essa identidade feminina vai aparecendo aos poucos a partir do interno e não de um dedo que aponta de fora, formatando-as como se não tivessem vida própria. Tais demonstrações são sugeridas mesmo quando há silêncio nessas vozes femininas, mas suas atitudes - não raro transgressivas - vão moldando suas vidas. É isto, em última análise, que acontece com Sara e virá a acontecer com Rebeca: na superfície da narrativa parecem condicionadas a uma identificação por fora, mas carregam consigo essa identificação que provêm do interior.

Essa característica distintiva coloca, uma vez mais, o traço da feminilidade como, de fato, matricial. A mulher e a terra, o feminino e a descendência, a origem e a sobrevivência aparecem como elementos arquetípicos de diversas sociedades antigas, realçando as características da natureza que se vinculam a esse mesmo traço feminino. Deve-se ressaltar que, nas culturas antigas, a mulher estava essencialmente ligada a terra e à agricultura, uma vez que os trabalhos referentes a essa esfera eram todos realizados por ela. Além disso, como 


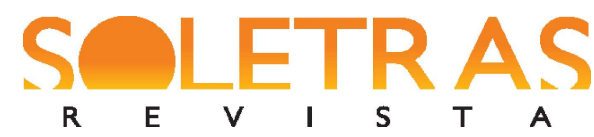

N. 38 - 2019.2 - ALTAMIR CELIO DE ANDRADE

já observou Júlio de Queiroz, os assuntos da família e os problemas dentro dos clãs estavam muito sujeitos à figura feminina:

\begin{abstract}
Numa sociedade em que todos os aspectos de aumento, tanto em quantidade material quanto em acréscimo familiar, tinham que passar pelo crivo do julgamento da mulher, a aceitação de um novo membro na família era, nessa época distante, exclusivamente decidida pela mulher. Até mesmo línguas de culturas já integradas no período histórico guardaram lembrança dessa autoridade feminina. No latim arcaico monium significa estado, assunto de (alguém). Daí matrimonium = assunto da mãe" (QUEIROZ, 2014, p. 18, grifos do autor).
\end{abstract}

O entre-lugar de Sara é simbólico das narrativas sobre várias mulheres da Bíblia. Isso nos permite identificar uma situação ambígua, que tanto pode valer para as mulheres quanto para os homens em questão: se as mulheres citadas são estéreis, os homens o são, também, a seu modo. Não se trata, aqui, de aprofundar o significado de "estéril" como possibilidade ou não de gerar filhos, mas como já foi indicado, tal sentido pode ser ampliado com bases sólidas na própria etimologia do termo 'aqarah.

Em todas essas narrativas, o interesse repousa menos nas raízes do que no deslocamento, no transitório e no fugaz. Esses eixos temáticos, presentes em grande parte da Bíblia, orientam os diversos relatos sobre mulheres. Elas são as geratrizes de sentido, cujo simbolismo do corpo e do acolhimento confere identidade a si mesmas e aos que se encontram ao seu redor.

Outro termo que ganha relevo nessas indicações é a ocorrência do verbo hebraico lakah (tomar), que sugere o sentido de posse. Estaria associado à captura de bens materiais, como despojos de guerra. Sara pertence a Abraão desde o primeiro momento em que entra em cena (Gn 11,29). A designação ishat 'abram (mulher de Abraão) aparece antes mesmo de seu nome ser indicado. Isso subordina sua história à história de seu marido. Com alguma facilidade, o significado do verbo lakah migra de bens materiais para a posse das mulheres por parte dos homens. Ao fim e ao cabo, isso não faz muita diferença, levando-se em conta que a mulher era considerada, de fato, uma posse do marido, sendo contada entre seus bens (casas, bois, burros e escravos). Tal situação fica claramente explicitada no último mandamento do decálogo. Em Exxodo 20,17, pode-se ler: "Não cobiçarás a casa de teu 
próximo, não cobiçarás (a) mulher de teu próximo, seu servo, sua serva, seu boi e seu burro". Esse mesmo mandamento tem ecos em Deuteronômio 5, 21.

Uma cena é especialmente emblemática para entendermos a identidade de Sara em relação ao patriarca. Trata-se de Gênesis 12,10-20. Ali, se diz que houve uma fome na terra e Abraão desceu ao Egito com sua mulher. Com medo de que o Faraó o matasse por causa (da beleza) dela, o patriarca a pede (por favor) que diga ser sua irmã e não esposa. O rosto de Sara é, portanto, o que vai permitir a sua sobrevivência e a de Abraão, bem como de toda a sua família diante do Faraó. Nesse primeiro momento da narrativa, o mistério do rosto de Sara fica delineado literalmente, quando se pode ler "és uma mulher bonita de se ver" (v.11). Os atributos femininos de Sara se convertem no fiel da balança para o bem estar ou a ruína de Abraão. Em todo o episódio, o nome dela aparece somente duas vezes, mas sua presença silenciosa é imponente no decorrer da narrativa:

- As coisas acontecem por causa (e ao redor) dela;

- Passa de mulher de Abraão a mulher do Faraó;

- É louvada por Abraão e pelos presentes por ser muito bela.

A despeito das referências à beleza de Sara - em oito dos onze versículos ela é chamada, ironicamente, apenas de mulher -, a narrativa parece mostrar, assim, que sua figura, ao mesmo tempo em que é retratada em linhas de aparente passividade, está diante dos homens como que (des)norteando seu pensar e agir. Sara, ali, em pé diante deles, exige que eles mesmos se autodefinam, para o bem ou para o mal, para a morte ou para a vida. Seu silêncio é eloquente, provocador e exigente de resposta.

A insistência de Abraão é realçada pela partícula hebraica na' (que podemos traduzir como "por favor"). Essa partícula realça, em muitas narrativas bíblicas, a necessidade de proteção de quem está em condição de fragilidade. A aparente figura de Sara, como joguete nas mãos dos dois homens (Abraão e Faraó), desvela, no seu silêncio, a dependência de ambos em relação a ela. Fica explicitado, na narrativa, o quanto o narrador (ou narradora) está interessado na figura da mulher: a sobrevivência de Abraão é por causa dela; os infortúnios do Faraó são por causa dela. 
O rosto-rosto (o primeiro estético e o segundo identidade) de Sara se converte num rosto-outro, ou seja, ela deixa de ser uma mulher bonita e subserviente para tomar as rédeas de sua própria história. Sara inaugura, então, o que temos chamado de "roustro". O paradoxo que se instaura coloca o que chega como aquele que interpela o que está. O que hospeda deve se reconfigurar frente ao rosto do que chega e reorientar a sua ética. Fica explicitado assim, o quando um deslocamento geográfico provou de deslocamento interno, forçando as personagens a se autodefinirem, relocalizando a si próprias bem como as que estão ao seu redor. Dessa forma, pensar o exílio é pensar a Hospitalidade, conceito caro aos nossos tempos e sobre o qual já refletimos em outro lugar.

Talvez se pudesse aproveitar, para benefício dessa reflexão, do pensamento de JeanLuc Nancy acerca do Exílio. Para ele, o exílio configura-se, dentre outras possíveis dimensões, como a saída de si próprio. Isso seria semelhante a sentir-se fora de lugar, fora do ser próprio, "fora da propriedade em todos os sentidos e, portanto, fora de lugar próprio como lugar natal, lugar nacional, lugar familiar, lugar da presença do próprio em geral" (NANCY, 1996, p. 34-35). Para o filósofo, nota-se um paradoxo, qual seja, o sair de um lugar próprio poderia revelar a desgraça par excellence e, ao mesmo tempo, significar a essência do exílio. Isso porque ele entende o exílio "como possibilidade positiva, a mais positiva, inclusive, do ser ou da existência: saída ou partida, distanciamento ou alienação, a desgraça é indispensável para a realização do ser" (NANCY, 1996, p. 36).

\section{Rebeca: a força inesperada de uma mulher estrangeira}

Rebeca é uma jovem estrangeira, mandada buscar por Abraão em sua terra natal para ser dada em casamento a seu filho Isaac. A razão para isso é simples: Abraão não queria para seu filho uma mulher de entre as da terra $(G n$ 24,3). Rebeca é filha de Batuel, portanto neta de Melca, a cunhada de Abraão (Gn 11,29). Repare-se, portanto, que não é Isaac que busca uma esposa para si, mas a iniciativa parte do patriarca. Há, inclusive, uma recomendação expressa de Abraão para que Isaac não seja reconduzido à sua terra $(G n$ 24,6.8). É um pormenor significativo: seria a sugestão de não se fazer um contradeslocamento? Uma volta à terra antiga? Sobre isso é difícil concluir. 
Quando Abraão envia seu servo a Haran, o leitor pode notar uma cena idílica junto ao poço. Durante e após as tratativas para o casamento, a segurança mostrada pela jovem Rebeca é um sinal distintivo de sua forte personalidade que vai acompanhá-la em toda a sua vida posterior. Eis o texto do seu encontro com Isaac:

\footnotetext{
${ }^{61}$ E se levantou Rebeca e suas servas, montaram sobre os camelos e seguiram atrás do homem. O servo tomou Rebeca e partiu. Isaac voltava do poço de Lahay Rô̂, ele habitava na terra do Negueb. ${ }^{63}$ Saiu Isaac a meditar no campo, pela tarde. Levantou seus olhos e eis que viu camelos que vinham. ${ }^{64}$ E Rebeca, levantando seus olhos, viu a Isaac e desceu de sobre o camelo. E disse ao servo: "quem é aquele homem, o que vem ao nosso encontro pelo campo?" ${ }^{65}$ O servo disse: "ele é meu senhor". (Ela) tomou o véu e se cobriu. ${ }^{66} \mathrm{E}$ o servo narrou a Isaac todas as coisas que fez. ${ }^{67} \mathrm{E}$ Isaac introduziu Rebeca na tenda de sua mãe Sarai; ele a tomou e ela se tornou sua mulher e ele a amou. E Isaac se consolou da morte de sua mãe (Gn 24,61-67) ${ }^{4}$.
}

A narrativa, embora breve, reproduz de maneira microcósmica o que ocorre em todo o capítulo 24 do Gênesis: as iniciativas são tomadas por Rebeca; ela aparece como sujeito de mais de dez verbos, destacando-se nitidamente em relação às atitudes de Isaac. Isso permite concluir um interessa bastante peculiar da narrativa para com a futura matriarca. Um paralelismo irônico presente no texto, parece exemplificar o que ora propomos: Isaac levantou seus olhos e viu camelos; Rebeca, levantando os seus, vê a Isaac. Ela, nas duas situações, não fora vista: primeiro porque os camelos são indicados e, depois, porque se cobre com o véu (Gn 24, 63-65).

Há, ainda, um outro detalhe que parece realçar a grandiosidade de Rebeca em relação à fragilidade de Isaac. Esse ponto situa-se na conclusão da narrativa. Nele, o narrador (ou narradora) sugere que o casamento de Isaac é um consolo da perda de sua mãe, Sara. O verbo lakah (tomar) perde, assim, toda a sua força e soa quase irônico. Nesse sentido, Isaac está mais para estrangeiro do que a própria Rebeca. Como observara Julia Kristeva, comentando $O$ Estrangeiro, de Albert Camus, tal "estrangeiro, portanto, é aquele que perdeu a mãe" (KRISTEVA, 1994, p. 13).

A estrangeiridade de Rebeca não é uma realidade que lhe eclipsa ou inibe, pelo contrário, ela manifesta-se, desde o princípio, como senhora das situações que lhe são apresentadas. Rebeca age com segurança e protagonismo tanto em sua terra como na terra de

\footnotetext{
${ }^{4}$ Tradução nossa do original hebraico.

SOLETRAS - Revista do Programa de Pós-Graduação em Letras e Linguística - PPLIN

Faculdade de Formação de Professores da UERJ

Número 38 (jul.-dez. 2019) - ISSN: 2316-8838

DOI: https://doi.org/10.12957/soletras.2019.43412
} 
Isaac. Sua chegada em casa de Isaac é indicativa de uma mudança no interior da tenda: a narrativa caminha para a sugestão de que é nesse momento que as coisas começarão a funcionar. Em Rebeca, não se verificam traços de dependência. Ao agir com liberdade e soberania, ela toma as rédeas das situações nas quais se envolve. O deslocamento de Rebeca de sua tenda para a tenda de Isaac vai provocar um deslocamento ainda maior nos rumos dessa família patriarcal. Por exemplo, no futuro evento das contendas entre seus dois filhos Esaú e Jacó, sua participação será crucial em toda a trama, sobrepujando, inclusive, Isaac. O resultado de suas ações é nada menos que a mudança na linha patriarcal de Israel, de modo que o pai do povo hebreu será Jacó e não Esaú. Sendo assim, a cegueira de Isaac, sugerida no relato, é como que uma linha que perpassa sua vida: Rebeca tem os olhos abertos e Isaac parece encerrado numa constante cegueira.

Grandes comentadores, como Gehard Von Rad (1982), Harold Bloom (1992) e Robert Alter (2007) não observaram, no entanto, um elemento que não parece circunstancial nos episódios que envolvem Rebeca: a raiz do seu nome $(r b q)$. Mesmo os dicionários que fizeram alusão a essa raiz foram relativamente incertos. Benjamin Davidson, em The analytical hebrew and chaldee lexicon, 1980 (Léxico Analítico do Hebraico e do Caldeu, não traduzido no Brasil), apesar de afirmar que é uma raiz que não ocorre no hebraico, indica que, em árabe, tal termo aludiria a amarra ou aperto, sendo usada para animais. Assim sendo, para Davidson, Rebeca poderia indicar ligação, envolvimento ou mesmo o ato de cativar, provavelmente no sentido de conquistar (DAVIDSON, 1980, p. 674). Portanto, a peculiaridade do nome de Rebeca e seu campo semântico podem sugerir que todas as suas ações estejam sob a égide desse caráter singular: ela não se deixa envolver, mas envolve.

Essa perspectiva comparece no episódio emblemático (supracitado) da interceptação que Jacó faz da bênção de seu pai Isaac (Gênesis 27). Desde o início, o episódio se revela conflitante: seja pela dificuldade de Rebeca em dar à luz, seja pela luta (já intrauterina) dos dois irmãos (Gn 25,19-34). No decorrer do capítulo 27 , no entanto, fica clara a participação de Rebeca na interceptação da bênção. É ela quem prepara os cabritos para que Jacó ofereça a seu pai como um prato que ele gosta $(v v \cdot 9.13)^{5}$. É ela, também, que encoraja o inseguro Jacó para que se apresente diante do pai devidamente disfarçado de Esaú (vv.13-17).

\footnotetext{
${ }^{5}$ Aliás, os relatos envolvendo cabritos têm sido cruciais no Gênesis. Além desse, os irmãos embeberão a túnica de José em sangue de cabrito e a apresentarão a Jacó, para seu desespero e angústia (37,31). Mais adiante, Judá 


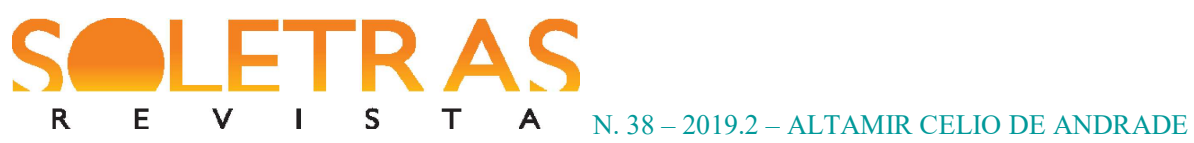

Nesse episódio, reaparece a cegueira de Isaac que é, evidentemente, natural. Rebeca, no entanto, permanece de olhos abertos. Um episódio futuro ( $G n 48,13-14)$, que parece relembrar a presente narrativa, é comentado de modo bastante contundente por Harold Bloom:

Com a aproximação de sua morte, o quase cego Jacó revive, de maneira deliberada, um aspecto da cena em que seu pai cego abençoou-o em lugar de seu irmão Esaú. Como verdadeiro filho de sua mãe, Rebeca, Jacó, que é Israel, astutamente cruza as mãos, pondo a direita sobre a cabeça de Efraim, o mais novo, e a esquerda sobre a de Manassés, o primogênito (BLOOM, 1992, p. 258).

A participação de Rebeca é, portanto, decisiva. Isso permite que notemos como a presença feminina é percebida nos relatos que são vitais para a história do povo. Os eventos são conflitivos, complexos, mas a estratégia feminina aparece em relevo, sendo destacada pela fina ironia da narrativa. $\mathrm{O}$ fato de Rebeca ter sido buscada em terra estrangeira - a mesma de onde veio Abraão - a aproxima de Sara; no entanto, seus traços são muito mais firmes que os de sua sogra, embora com ela se repitam algumas das histórias que se passaram com Sara. Veja-se, por exemplo, o episódio onde Isaac também apresenta Rebeca como sua irmã para não morrer (Gn 26,1-14). Tal realidade deixa aparecer com muita nitidez o protagonismo feminino. Harold Bloom havia observado isso quando compara homens e mulheres nessas narrativas matriciais para sugerir a autoria feminina nos relatos:

Os únicos adultos em J são mulheres: Sarai, Rebeca, Raquel, Tamar. Isaac é sempre um bebê, Abrão e Judá facilmente caem na infantilidade, e os dois homens de aguda sensibilidade - Jacó e José, pai e verdadeiro filho permanecem, até morrerem, com temperamentos mimados e talentosos, infantis ao extremo (BLOOM, 1992, p. 252).

A presença de Rebeca em terra estrangeira e masculina fecha e abre ciclos: o começo de sua ação está no fim da vida de Sara. Essa percepção ultrapassa as possibilidades de análise do presente artigo, uma vez que podem ser identificadas inúmeras outras personagens femininas da Bíblia que se utilizam de recursos semelhantes aos dessas mulheres para os desenvolvimentos de suas vidas, maternidades e estratégias de sobrevivência. A título de exemplo, podem ser citados os estratagemas de Tamar (Gn 38), a perspicácia das parteiras do

será enganado por Tamar ao fazer a ela a oferta de um cabrito a fim de ter seus serviços sexuais $(38,17)$. Em todos os episódios há uma perspectiva de engano ao redor do animal. 


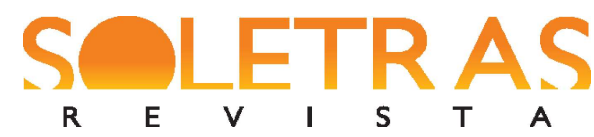

N. 38 - 2019.2 - ALTAMIR CELIO DE ANDRADE

Egito (Ex1), as artimanhas da prostituta Raab (JS 2) bem como toda a Saga de Rute no livro que leva seu nome. Como elas tantas outras, tanto do Antigo quanto do Novo Testamento.

Nos casos presentes de Sara e Rebeca, pode ser notado um sensível crescendum: o próprio nome de Rebeca, como indicado, alude a perspectivas novas que não tinham sido apresentadas nos episódios ao redor de Sara. As proximidades, no entanto, se fazem notar quando alguns elementos são destacados: o conflito que envolve as descendências (Isaac e Ismael, para Sara; Esaú e Jacó, para Rebeca); a passividade dos patriarcas (Abraão e Isaac); a dificuldade em gerar filhos por parte das duas mulheres; as estratégias femininas que norteiam os relatos sobre essas mesmas mulheres.

\section{Considerações finais}

A reflexão proposta por este artigo teve como objetivo avaliar os deslocamentos de duas mulheres bíblicas: Sara e Rebeca. Essas personagens, no horizonte dos estudos bíblicos, configuram-se como modelos para uma análise dos deslocamentos humanos em todos os tempos e lugares. A tradição do antigo povo hebreu teve como característica fundante suas constantes mudanças territoriais, o que implicou, sobremaneira, em suas mudanças internas que formataram o futuro de sua cultura.

Traço emblemático de Sara e Rebeca, dentre outras mulheres, é sua estrangeiridade em relação ao lugar onde sua descendência vai sobreviver. Essa realidade será, talvez, uma das mais essenciais para tudo o que possa advir de uma mudança e suas implicações no interno da pessoa. No interior dessas narrativas, notamos que a corporeidade, o silêncio e as estratégias de sobrevivência permitem entender melhor os deslocamentos e horizontes do eixo mulhercorpo-exílio. Fica, portanto, bastante evidenciado como elas compartilham um deslocamento geográfico e interior. Quando saem de suas tendas familiares para adentrarem tendas estrangeiras de novos clãs, vão com elas toda uma identidade que pode se suprimida, pisoteada e esquecida. É aí, portanto, que seu modo de comportar e entender o mundo ao seu redor terá que ser completamente revisitado para que possam, sobretudo, sobreviver.

As situações em que se encontram enredadas oferecem desafios os mais diversos. A saídas criativas propostas por elas são o diferencial que recolocará suas vidas nos trilhos da 
identidade. Para tanto, é preciso que elas se reconfigurem, fazendo com que se verifique o que temos entendido por deslocamento.

Quando escolhemos as narrativas ao redor de Sara e Rebeca, longe de representar unicamente um exercício acadêmico, sugerimos que se vá ao texto bíblico com a percepção de que o mesmo é autônomo, permeado de informações que fazem dele uma fonte inesgotável para o trabalho interpretativo. Reconhecemos, portanto, que cada texto em separado carrega em si um conjunto de sentidos que pode ser lido e avaliado em justaposição a outros tantos no interior da própria Bíblia e fora dela. Além disso, as características que revelam os elementos culturais de um povo, sua forma de escrita, seu pensamento e orientação no mundo podem ser aplicados a diversos outros setores do conhecimento e da experiência humanas. Fundamentalmente, nossa análise dialoga com o modo como os principais autores estudados também desenvolvem seus pensamentos, ou seja, a partir de pormenores da língua, uma vez que oferecem oportunidades para uma nova compreensão do ser humano no mundo que o circunda.

Se, por um lado, o uso da Bíblia tradicionalmente se pautou numa visada que tinha a Teologia como hermenêutica norteadora, oferecendo as bases de sua sistematização, por outro, cumpre notar que uma abordagem dos textos como a apresentada por este artigo não vai de encontro com essa forma de ler a Bíblia. Afirmamos, portanto, que ler os textos bíblicos a partir do que foi proposto permite, inclusive, a sugestão de que o seu aspecto teológico precisa ser repensado, já que sua fundamentalidade se altera a partir de uma abordagem atual dos conceitos, quais sejam, os de exílio, deslocamento e hospitalidade, precipuamente.

Este exame buscou evidenciar o papel e o valor individual de cada uma das mulheres estudadas. Ele possibilitou a constatação de que elementos presentes na vida de cada uma delas ecoaram nas vidas e comportamentos de outras, em realidades e tempos históricos diferentes. Além disso, os conceitos abordados - e aqui já nomeados -, além e terem contribuído para nortear as reflexões sobre elas, excedem os seus momentos vivenciais, servindo, assim, de base para a abordagem da história de outras mulheres, encontradas não só em narrativas como as da própria Bíblia, como também em outros povos de outros tempos e lugares. 


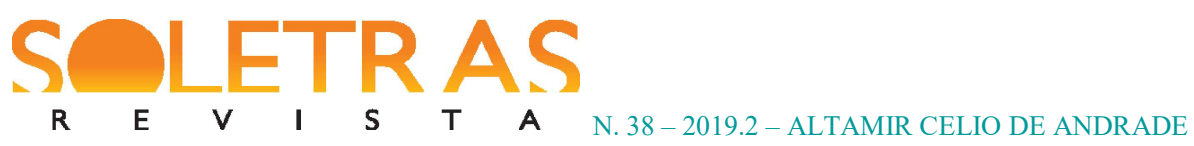

\section{Referências}

ALTER, Robert. A arte da narrativa bíblica. Tradução: Vera Pereira. São Paulo: Companhia das Letras, 2007.

AUERBACH, Erich. "A cicatriz de Ulisses". In: AUERBACH, Erich. Mimesis: a representação da realidade na literatura ocidental. $4^{\mathrm{a}}$ ed. Tradução: George Bernard Sperber. São Paulo: Editora Perspectiva, 1998.p. 1-20.

BLOOM, Harold. O livro de J. Tradução: Monique Balbuena. Rio de Janeiro: Imago, 1992.

CHWARTS, Suzana. Uma visão da esterilidade na Bíblia hebraica. São Paulo: Associação Editorial Humanitas, 2004.

DAVIDSON, Benjamin. The analytical hebrew and chaldee lexicon. Grand Rapids: Zondervan Publishing House, 1980.

ELLIGER, Karl; RUDOLPH, Wilhelm (Eds.). Biblia hebraica stuttgartensia. 5a. ed. Stuttgart: Deutsche Bibelgesellschaft, 1997.

FRYE, Northrop. $O$ código dos códigos: a Bíblia e a literatura. Tradução: Flávio Aguiar. São Paulo: Boitempo, 2004.

HALL, Stuart. Da diáspora: identidades e mediações culturais. Tradução: Adelaine La Guardia Resende. Belo Horizonte: Editora UFMG; Brasília: Representação da UNESCO no Brasil, 2003.

KRISTEVA, Julia. Estrangeiros para nós mesmos. Tradução: Maria Carlota Carvalho Gomes. Rio de Janeiro: Rocco, 1994.

NANCY, Jean-Luc. La existencia exiliada. Tradução de Juan Gabriel López Guix. Archipielago, Barcelona, v. 26-27, p. 34-39, 1996.

QUEIROZ, Júlio de. A mulher na humanidade. Blumenau: Edifurb, 2014.

SARAMAGO, José. A jangada de pedra. Rio de Janeiro-São Paulo: Record, 1980.

VON RAD, Gerhard. El libro del Genesis. Tradução: Santiago Romero. Salamanca: Ediciones Sigueme, 1982.

\section{About faces and distances: Displacements in the biblical narratives of Sarah and Rebekah}

\footnotetext{
Abstract: This paper examines the biblical narratives about Sarah and Rebekah. These characters, who are present in the Book of Genesis, are symbolic for thinking of spatial displacement as an 


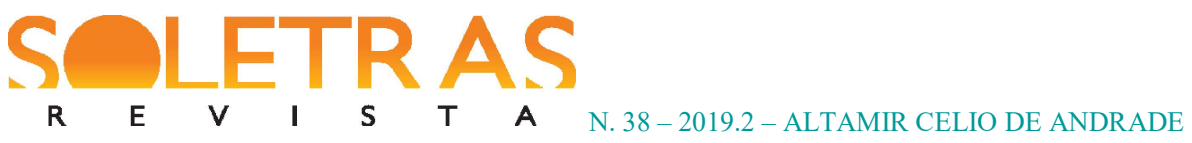

indication of internal transformations, that is, psychological issues that will accompany these women throughout their experiences in foreign lands. The Genesis writes the first pages of a classic: the Bible. It is such an emblematic work which has much influenced western thinking, as have Erich Auerbach, Northrop Frye, Robert Alter, and Harold Bloom, among others. The stories of these two women are references for reading a founding text of the ancient hebrews, since, in them, Israel will recognize its origin, its origins and the sense of its existence as a people. This proposed investigation will let itself be guided mainly by the literary, cultural, and philosophical studies from the works of Stuart Hall and Jean-Luc Nancy. Therefore, it can be anticipated that the study of the behavior of these two characters, as well as their strategies of survival, allows us understanding the displacement of human beings in all times and in different parts of the world. The suffering, astuteness, and identities of Sarah and Rebekah enable us to reread the history of old Israel in a vivid, aesthetically and exciting way.

Keywords: Sarah. Rebekah. Displacement. Identity.The Bible.

Recebido em: 23 de julho de 2019.

Aceito em: 09 de setembro de 2019. 